\title{
Sex Differences in Suicides Among Children and Youth: The Potential Impact of Misclassification
}

\author{
Anne E. Rhodes, $\mathrm{PhD},{ }^{1-4}$ Saba Khan, $\mathrm{MPH},{ }^{4}$ Michael H. Boyle, $\mathrm{PhD},{ }^{5}$ Christine Wekerle, $\mathrm{PhD},{ }^{6}$ \\ Deborah Goodman, PhD, ${ }^{7,8}$ Lil Tonmyr, PhD, ${ }^{9}$ Jennifer Bethell, MSc, ${ }^{1,3}$ Bruce Leslie, MSW, ${ }^{8,10}$ Ian Manion, PhD ${ }^{11}$
}

\section{ABSTRACT}

Objectives: We examined whether established sex differences in suicide rates persist when adjustments are made for potential misclassification of deaths in children and youth.

Methods: This is a retrospective, descriptive study of 1,294 suicides, 961 accidental and 254 undetermined deaths occurring between January 1 , 2000 and December 31, 2007, among persons aged 10 to 25 years in Ontario, Canada. Using data from Coroner's records, causes of death were reclassified based on two different misclassification criteria. Actual and reclassified suicide rates were calculated by sex and age group (with $95 \%$ confidence intervals) and by year of death.

Results: Males aged 16-25 years accounted for the majority of suicides (68.9\%). Asphyxia was the most common cause of suicide in both sexes. While suicides by shooting were almost exclusive to males, suicides due to alcohol/drug toxicity were significantly higher in females. Both before and after reclassification of suicide deaths, sex differences in suicide rates emerged in the 16-25 years age group. In each study year, both actual and reclassified suicide rates were higher in males than females.

Conclusions: Sex differences in suicide rates emerging in adolescence are unlikely to be due to misclassification. Other proposed explanations for sex differences in youth suicide rates should be investigated further.

Key words: Suicide; adolescent; child; cause of death; sex differences; suicide misclassification

$\mathrm{S}$ uicide is the second leading cause of death among persons aged 15-24 in Canada. ${ }^{1}$ Suicide is a rare event in children/youth; ${ }^{2}$ however, it contributes substantially to premature mortality worldwide ${ }^{3}$ and is a devastating life event for loved ones that may lead to broader imitation effects. ${ }^{4}$ Suicide rates typically increase during the transition from childhood to adolescence and, in most regions of the world, including Canada, are higher in males. ${ }^{2,5,6}$ This may arise from sex differences in psychopathology, suicidal intent, access to methods, helpseeking or ascertainment of death. ${ }^{7}$ Such explanations have not been thoroughly examined in children/youth. A fuller understanding of sex differences in youth suicide rates is needed to ensure that suicide prevention strategies are built on accurate data.

This study addresses the "ascertainment" explanation; in particular, the possible misclassification of suicides in boys and girls. Suicides in general are thought to be under-reported as accidental or undetermined deaths in many jurisdictions. Decedents or their loved ones may not leave or provide evidence suggestive of suicide for reasons of shame, stigma, or invalidation of life insurance. ${ }^{8}$ Furthermore, certain causes of death, such as alcohol/drug overdose, pose greater uncertainty in suicide classification. ${ }^{9}$

Among youth, sex differences may arise from differential underreporting of suicides in females compared to males. ${ }^{7}$ However, few studies have actively investigated misclassification of suicides in children/youth. In the United States (US), potential changes in sui-

\section{Author Affiliations}

1. The Suicide Studies Research Unit and the Keenan Research Centre at the Li Ka Shing Knowledge Institute of St. Michael's Hospital, Toronto, ON

2. Department of Psychiatry, Faculty of Medicine, University of Toronto, Toronto, ON

3. Dalla Lana School of Public Health, Faculty of Medicine, University of Toronto Toronto, ON

4. The Institute for Clinical Evaluative Sciences, Toronto, ON

5. Department of Psychiatry and Behavioural Neurosciences and Offord Center for Child Studies, McMaster University, Hamilton, ON

6. Department of Pediatrics, McMaster University, Hamilton, ON

7. The Children's Aid Society of Toronto, Child Welfare Institute, Toronto, ON

8. Factor-Inwentash Faculty of Social Work, University of Toronto, Toronto, ON

9. The Injury and Child Maltreatment Section, Health Surveillance and Epidemiology Division, Public Health Agency of Canada, Ottawa, ON

10. The Catholic Children's Aid Society of Toronto, Toronto, ON

11. The Ontario Centre of Excellence for Child and Youth Mental Health, Ottawa, ON Correspondence: Dr. Anne E. Rhodes, 2 Shuter Wing, Suite 2010f, St. Michael's Hospital, 30 Bond Street, Toronto, ON M5B 1W8, Tel: 416-864-6060, ext. 2693, Fax: 416-864-5996, E-mail: RhodesA@smh.ca

Acknowledgements: Funding for this project was provided by an operating grant from the Canadian Institutes of Health Research, MMG 103246. This study was supported by the Institute for Clinical Evaluative Sciences, which is funded by an annual grant from the Ontario Ministry of Health and Long-Term Care, and the Office of the Chief Coroner for Ontario. In addition, we acknowledge the support of The Child Welfare League of Canada, the Ontario Association of Children's Aid Societies, the Ontario Centre of Excellence for Child and Youth Mental Health, and the Injury and Child Maltreatment Section, Health Surveillance and Epidemiology Division, Public Health Agency of Canada. A special thanks to June Lindsell, Anne Marie Mior Monique Kerr-Taylor and Nancy Cooper for their assistance in data collection. Preliminary results of this study were presented at the Canadian Association for Suicide Prevention conference in Vancouver, Canada in October, 2011.

Disclaimer: The opinions, results and conclusions reported in this paper are those of the authors and do not necessarily reflect the official policy or position of the affiliated or acknowledged organizations. No endorsement by these organizations is intended or should be inferred.

Conflict of Interest: None to declare. 
Table 1. Reclassification Criteria for Suicides, Accidental and Undetermined Deaths

\begin{tabular}{|c|c|c|c|}
\hline & \multicolumn{2}{|l|}{ Criterion A } & \multirow[b]{2}{*}{$\begin{array}{c}\text { Criterion B } \\
\text { All UD } \\
\Downarrow \\
\text { Suicides } \\
\text { N=253 Reclassified } \\
\text { N (\%) }\end{array}$} \\
\hline Indicators Across Death Factors & $\begin{array}{c}\text { A1: } \\
\text { Suspect ACC or UD } \\
\Downarrow \\
\text { Suicides } \\
\text { N=186 Reclassified } \\
\mathbf{N}(\%) \\
\text { Reported recent suicidal } \\
\text { communication in month prior } \\
\text { to death } \\
16(8.6 \%)\end{array}$ & $\begin{array}{c}\text { A2: } \\
\text { Suspect suicides } \\
\Downarrow \\
\text { UD } \\
\text { N<6* Reclassified } \\
\text { N (\%) }\end{array}$ & \\
\hline \multirow{2}{*}{$\begin{array}{l}\text { Indicators Specific to Death Fact } \\
\text { Asphyxia }\end{array}$} & & & \\
\hline & & $\begin{array}{l}\text { History of choking game } \\
N<6^{*} \\
\text { Evidence of autoerotic activity } \\
N<6^{*}\end{array}$ & $29(11.5 \%)$ \\
\hline Shooting & & $\begin{array}{l}\text { Evidence of recreational activity } \\
\qquad \mathrm{N}<6^{*}\end{array}$ & $6(2.4 \%)$ \\
\hline Motor vehicle collision & $\begin{array}{l}\text { Single-occupant driver, no evidence of: } \\
\text { - Hazardous weather } \\
\text { - Vehicle malfunction } \\
146(78.5 \%) \\
\text { Pedestrian hit by rail train or subway, } \\
\text { no evidence of: } \\
\text { - Occupational activity } \\
\quad 24(12.9 \%)\end{array}$ & & $27(10.7 \%)$ \\
\hline $\begin{array}{l}\text { Drowning } \\
\text { Alcohol/drug toxicity } \\
\text { Fall/jump } \\
\text { Other }\end{array}$ & & & $\begin{array}{l}17(6.7 \%) \\
65(25.7 \%) \\
11(4.3 \%) \\
98(38.7 \%)\end{array}$ \\
\hline
\end{tabular}

ACC: Accidental deaths, UD: Undetermined deaths.

* Small cells $(\mathrm{n}<6)$ and corresponding proportions suppressed to protect confidentiality.

cide time trends (1979-1994) among those aged 10-24 were examined by reclassifying suspect causes of death and undetermined deaths to suicides. ${ }^{8}$ While suicide rates were not altered appreciably, upward corrections were most apparent in the 10-14 age group and in Black males. In Norway, ${ }^{10}$ suicides under age 15 were compared to suicides in 15-19 year olds. Half of suicides under age 15 were reclassified as equivocal or not suicides, compared to $4 \%$ of suicides in 15-19 year olds. In a US national survey, 94 members of the National Association of Medical Examiners were asked about factors related to making a suicide determination in children. ${ }^{11}$ All respondents identified a suicide note and most identified a history of suicidal ideations or behaviours; however, responses varied regarding the minimum age at which respondents would classify a child death as a suicide.

Altogether, these studies imply that suicide deaths may be either under- or over-reported among different age groups, but it remains unclear if reclassification impacts observed sex differences in suicide rates. The objective of this study was to examine sex differences in suicide rates in children and youth in Ontario after adjusting for potential misclassification of death.

\section{METHODS}

\section{Study design}

This is a retrospective study of suicide, accidental and undetermined deaths in children and youth (aged 10-25 years) who had been living in Ontario and died between January 1, 2000 and December 31, 2007. Data access was granted under a data sharing agreement between the Office of the Chief Coroner for Ontario (OCC) and the Institute for Clinical Evaluative Sciences (ICES), both in Toronto, Ontario. This study was approved by the Research Ethics Boards of St. Michael's Hospital and Sunnybrook Health Sciences Centre in Toronto.

\section{Participants}

All suicides $(\mathrm{n}=1,299)$, all undetermined deaths $(\mathrm{n}=256)$, and a random sample of one third of accidental deaths $(n=966)$ in the aforementioned age and time ranges were selected. Of these 2,521 deaths, 9 had files that could not be located and 4 were excluded based on eligibility criteria (i.e., they were outside of age range). Thus, a total of 2,508 cases were analyzed (1,294 suicides, 254 undetermined deaths, 961 accidental deaths).

\section{Setting}

All data were obtained from paper case files held at the OCC. In Ontario, a coroner is a licensed physician appointed to investigate medico-legal deaths within the province according to the Coroners Act, R.S.O. 1990, c. C.37.12 Most of these deaths have occurred suddenly or unexpectedly. Individual case files contain the Coroner's Investigation Statement (a narrative summary of the circumstances of death) and additional documentation, including police reports.

\section{Data measures}

Case files were reviewed by professional chart abstractors who entered data into an encrypted electronic database in a secure location at the OCC. Data were electronically transmitted and housed at ICES in a secure fashion. Agreement between each abstractor pair was assessed for all study variables in a subset of $5 \%$ of case files $(n=121)$. Kappa values on study variables ranged from $0.58-1.0$, indicating substantial to almost perfect agreement. ${ }^{13}$ The following variables were analyzed:

- Age, sex, living situation: Identified at time of death.

- Death factor: Standardized cause-of-death coding used by investigating coroners. As in the literature, ${ }^{2,5}$ the major causes of unnatural deaths are: asphyxia, alcohol/drug toxicity, drowning, shooting, fall/jump, and motor vehicle collision (Kappas $\geq 0.88$ ). Specific information about each death factor was abstracted where possible. 
Table 2. Characteristics of Suicide Cases, by Sex $(n=1294)$

\begin{tabular}{|c|c|c|c|c|c|c|}
\hline & \multicolumn{3}{|c|}{ Males } & \multicolumn{3}{|c|}{ Females } \\
\hline & $\begin{array}{c}\mathbf{N} \\
966\end{array}$ & $\begin{array}{l}\text { \%* }^{*} \\
75\end{array}$ & $(95 \% \mathrm{CI})$ & $\begin{array}{c}\mathbf{N} \\
328\end{array}$ & $\begin{array}{c}\% \\
25\end{array}$ & $(95 \% \mathrm{CI})$ \\
\hline \multicolumn{7}{|l|}{ Age (years) } \\
\hline $10-15$ & 75 & 7.8 & $(6.1-9.4)$ & 64 & 19.5 & $(15.2-23.9)$ \\
\hline $16-25$ & 891 & 92.2 & $(90.5-93.9)$ & 264 & 80.5 & $(76.2-84.8)$ \\
\hline \multicolumn{7}{|l|}{ Living situation } \\
\hline Lived with biological parents & 526 & 54.4 & $(51.4-57.6)$ & 172 & 52.4 & $(47.0-57.8)$ \\
\hline Lived alone & 68 & 7.0 & $(5.4-8.7)$ & 27 & 8.2 & $(5.2-11.2)$ \\
\hline Lived with friends/roommates & 67 & 6.9 & $(5.3-8.5)$ & 25 & 7.6 & $(4.7-10.5)$ \\
\hline Lived with spouse/partner & 66 & 6.8 & $(5.2-8.4)$ & 21 & 6.4 & $(3.7-9.0)$ \\
\hline Lived with other family members & 38 & 3.9 & $(2.7-5.2)$ & 19 & 5.8 & $(3.3-8.3)$ \\
\hline Other & 75 & 7.8 & $(6.1-9.5)$ & 21 & 6.4 & $(3.7-9.0)$ \\
\hline Unknown & 126 & 13.0 & $(10.8-15.1)$ & 43 & 13.1 & $(9.4-16.8)$ \\
\hline \multicolumn{7}{|l|}{ Community size (population) } \\
\hline $1,500,000+$ & 244 & 25.3 & $(22.5-28.0)$ & 93 & 28.4 & $(23.5-33.2)$ \\
\hline $500,000-1,499,999$ & 100 & 10.4 & $(8.4-12.3)$ & 30 & 9.2 & $(6.0-12.3)$ \\
\hline $100,000-499,999$ & 265 & 27.4 & $(24.6-30.2)$ & 79 & 24.1 & $(19.4-28.7)$ \\
\hline $10,000-99,999$ & 90 & 9.3 & $(7.5-11.2)$ & 21 & 6.4 & $(3.7-9.0)$ \\
\hline$<10,000$ & 211 & 21.8 & $(19.2-24.4)$ & 87 & 26.5 & $(21.7-31.3)$ \\
\hline Unknown & 56 & 5.8 & $(4.3-7.3)$ & 18 & 5.5 & $(3.0-8.0)$ \\
\hline \multicolumn{7}{|l|}{ Neighbourhood income quintile } \\
\hline 1 (lowest) & 234 & 24.2 & $(21.5-26.9)$ & 75 & 22.9 & $(18.3-27.4)$ \\
\hline 2 & 138 & 14.3 & $(12.1-16.5)$ & 46 & 14.0 & $(10.3-17.8)$ \\
\hline 3 & 185 & 19.2 & $(16.7-21.6)$ & 52 & 15.8 & $(11.9-19.8)$ \\
\hline 4 & 169 & 17.5 & $(15.1-19.9)$ & 54 & 16.5 & $(12.4-20.5)$ \\
\hline 5 (highest) & 154 & 15.9 & $(13.6-18.2)$ & 55 & 16.8 & $(12.7-20.8)$ \\
\hline Unknown & 86 & 8.9 & $(7.1-10.7)$ & 46 & 14.0 & $(10.3-17.8)$ \\
\hline \multicolumn{7}{|l|}{ Death factor } \\
\hline Asphyxia & 601 & 62.2 & $(59.2-65.3)$ & 195 & 59.4 & $(54.1-64.8)$ \\
\hline Fall/jump & 105 & 10.9 & $(8.9-12.8)$ & 34 & 10.4 & $(7.1-13.7)$ \\
\hline Shooting & 119 & 12.3 & $(10.2-14.4)$ & $<6 \dagger$ & - & - \\
\hline Alcohol/drug toxicity & 39 & 4.0 & $(2.8-5.3)$ & 64 & 19.5 & $(15.2-23.8)$ \\
\hline Motor vehicle collision & 67 & 6.9 & $(5.3-8.5)$ & 20 & 6.1 & $(3.5-8.7)$ \\
\hline Drowning & 19 & 2.0 & $(1.1-2.8)$ & $<6 \dagger$ & - & - \\
\hline Other & 16 & 1.7 & $(0.8-2.5)$ & 6 & 1.8 & $(0.4-3.3)$ \\
\hline
\end{tabular}

Cl: Confidence Interval.

* Percentages may not add to $100 \%$ due to rounding.

$\dagger$ Small cells $(<6)$ and corresponding proportions and confidence intervals are suppressed to protect confidentiality.

- Means of death: Standardized death classification coding (Kappas $\geq 0.95$ ) defined according to OCC: ${ }^{14}$

- Accident: Death caused by an external factor, where death or harm was not foreseen or expected.

- Suicide: Death resulting from an intentional act of a person knowing the probable consequence of his/her actions. While the legal test to be satisfied is a balance of probability, a determination of suicide can only be made where there is clear and convincing evidence.

- Undetermined: Death where there is no evidence for any specific classification; or there is equal evidence or a significant contest among two or more classifications; or the death is a suicide that does not meet the legal test requiring a high degree of probability or an apparent suicide under age 10 (as young children tend not to appreciate the consequences of a suicidal act $\left.^{15}\right)$.

- Evidence of pre-suicidal behaviour: Evidence of any suicidal communications in month prior to death, including verbal, written or other communication (e.g., Internet chat) (Kappas $\geq 0.70$ ).

- Community size, neighbourhood income quintile: These residential variables were created at ICES for subjects identified within the Ontario Registered Persons Database (RPDB) as having an active Ontario health card and valid Ontario postal code at the time of their death (94\% of the study population). ${ }^{16}$ Postal code information from the RPDB and the Statistics Canada Postal Conversion File ${ }^{17}$ were used to assign each subject's residence to its dissemination area (the smallest geographic unit for which census data are produced $)^{18}$ to define these variables.

\section{Reclassification of death}

Means of death were reclassified using an approach similar to Mohler and Earls. ${ }^{8}$ Two different reclassification criteria were tested:

Criterion A: Suspect accidental and undetermined deaths (see Table 1) were reclassified to suicides (Criterion $A_{1}$ ). "Suspect" indicators of suicide were identified from the literature, across all death factors (e.g., recent suicidal communications ${ }^{10,11,19}$ ) and for specific death factors (e.g., single-occupant vehicle deaths ${ }^{8,19-}$ ${ }^{21}$ ). As it was possible some deaths classified as suicides were actually undetermined, particularly with regard to those under age $15,{ }^{10}$ we also reclassified certain suicide deaths to be undetermined, e.g., deaths with evidence of recreational activity (Criterion $\mathrm{A}_{2}$ ).

Criterion B: All undetermined deaths were reclassified to suicides.

\section{Analysis}

Analyses were conducted in SAS 9.2. Counts and proportions for all demographic variables and death factors were calculated by sex for suicide cases, with 95\% confidence intervals (CIs). Actual and reclassified suicide rates were calculated for all subjects linked to the RPDB, by sex, age group, and year of death, with 95\% CIs. (An accidental death was weighted by three to represent the total number of deaths). Non-overlapping 95\% CIs indicated a known statistically significant difference. ${ }^{22}$ Annually-adjusted Census population data from Statistics Canada were used for rate denominators. 


\section{RESULTS}

\section{Study population characteristics}

Table 2 displays demographic characteristics of the suicide deaths by sex. The majority (75\%) occurred in males, particularly in those aged 16-25 years. Just over 50\% of cases lived with their biological parents at the time of their death. There were no obvious sex differences in living arrangement or community population size/income level.

\section{Death factors}

Asphyxia was the most common cause of suicides in both males and females (Table 2). Most asphyxia deaths (92\%) were hangings across both sexes. There were no significant sex differences in causes of suicide, except for alcohol/drug toxicity and shooting. Suicides by shooting were almost exclusive to males and $84 \%$ involved long guns (e.g., rifles, shotguns). Conversely, suicides due to alcohol/drug toxicity were significantly higher in females than males (19.5\% vs. $4.0 \%, \mathrm{p}<0.0001)$. Among alcohol/drug suicides, the most commonly reported substances associated with death were: opioids (36\% and $20 \%$ in males and females, respectively) and anti-depressants (26\% and 33\% in males and females, respectively). Twentyseven percent of suicides reported multiple (2+) types of substances involved with death. There were no significant sex differences in types of substances involved in death. Among undetermined deaths, the most common cause of death was alcohol/drug toxicity, accounting for about one quarter of undetermined deaths in both sexes. Among accidental deaths, motor vehicle collisions were most common (67.4\% of males and $76.1 \%$ of females).

\section{Suicide rates and reclassification}

The average annual suicide rate over the study period was 8.48 per 100,000 in males and 3.02 per 100,000 in females. When rates were examined by age group, children/youth aged 16-25 had significantly higher rates than those aged 10-15 years (Figure 1 ). This pattern remained when suicides were reclassified using Criterion A or B. Sex differences in both actual and reclassified rates presented in the 16-25 year olds. Among this age group, the application of Criterion $\mathrm{A}$ had a greater impact on suicide rates in males than in females.

In each study year, actual suicide rates were significantly higher in males than females (see Figures 2 and 3). Sex differences remained stable upon reclassification of suicides using Criterion $\mathrm{A}$ or B. Of note, among males, Criterion A reclassified rates were almost always significantly higher than the actual suicide rates in each year.

\section{DISCUSSION}

Sex differences in actual and reclassified suicide rates emerged between the 10-15 and 16-25 year age groups. In each year, both actual and reclassified suicide rates were higher in males than in females. Thus, it is unlikely that sex differences in suicide rates emerging in adolescence are due to potential misclassification.

\section{Limitations}

There is no gold standard for suicide determination; therefore, "true" rates remain unknown. Reclassifying deaths provides an opportunity to test the robustness of sex differences in suicide rates

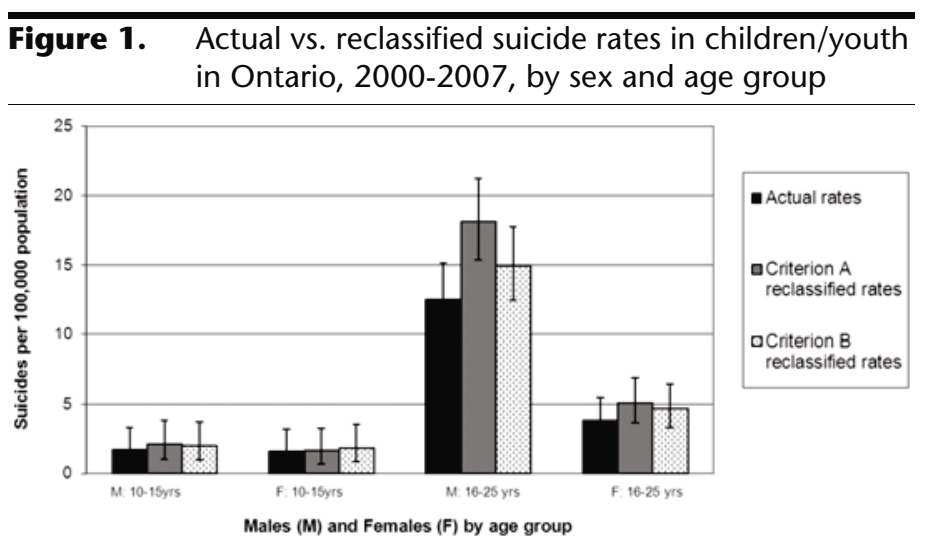

Figure 2. Actual vs. Criterion A suicide rates in children/youth in Ontario, annually by sex

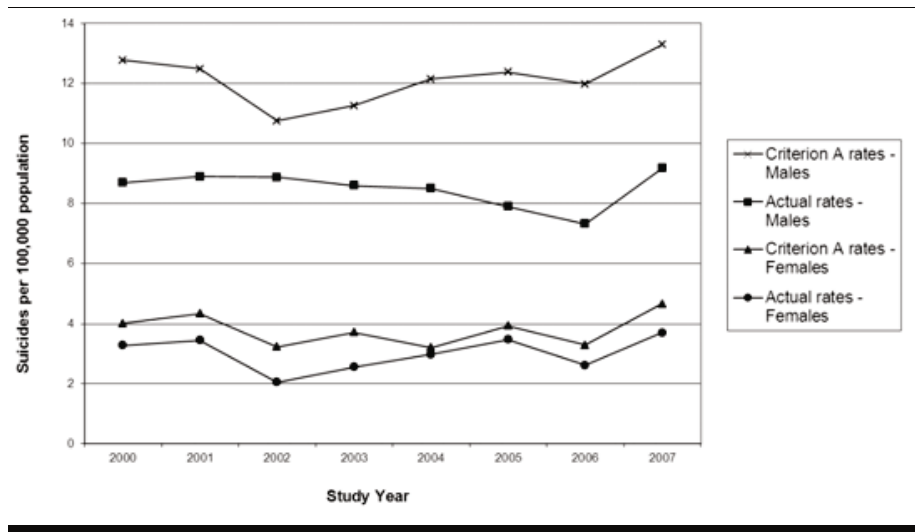

Figure 3. Actual vs. Criterion B suicide rates in children/youth in Ontario, annually by sex

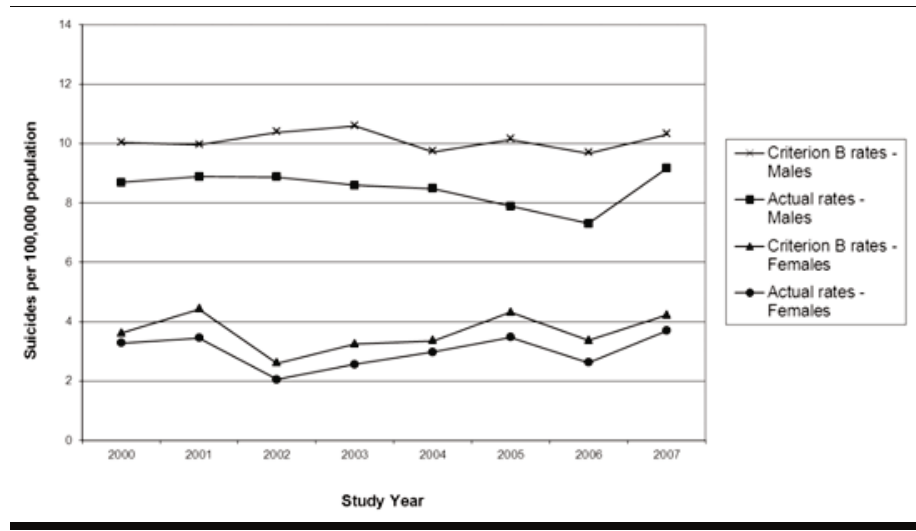

by age and over time. However, our criteria for reclassifying suicides must be contextualized. For example, it would be inappropriate to apply Criterion A in settings where there is limited access to cars and trains. Furthermore, if suicides under age 10 were officially recognized, undetermined deaths under age 10 would have been reclassified as suicides under Criterion B. Still, the number of undetermined deaths in 2000-2007 for children ages 5 to 9 was quite low (<10 deaths), minimally impacting our findings.

The selection of Criterion A was based on existing literature and heavily influenced by motor vehicle collisions, particularly with regard to single-occupant vehicle deaths. While abstractor agreement on recent suicidal communications was substantial, there is no standard requiring that it be assessed in these or other accidents. Thus, without further investigation, suspicious motor vehicle collision deaths may be better conceptualized as falling along a con- 
tinuum of risky behaviours with varying or undetermined intent. ${ }^{23,24}$ We were unable to identify specific criteria to reclassify other suspect "accidental" causes of death as suicides, especially alcohol/drug deaths. While some have suggested that multiple drug consumption prior to death may indicate suicidal intent, ${ }^{25}$ it is also possible that the decedent misjudged the effect or tolerance of additional drugs, especially during a relapse.

\section{CONCLUSIONS}

Sex differences in suicide rates emerging in adolescence are unlikely to be the result of misclassification of suicides. However, for the purpose of reporting absolute counts or rates of suicide, underreports should not be discounted. In particular, differences between actual and reclassified rates were most evident among males aged 16-25 years when Criterion A was applied. When testing associations of risk/protective factors with suicide in children/youth, given a strict definition of suicide, it seems unlikely that associations found would be invalidated by suicide misclassification. Other proposed explanations for the emergence of sex differences in suicide rates in adolescence merit further investigation.

\section{REFERENCES}

1. Statistics Canada. Leading Causes of Death in Canada, 2008. Available at: http://www.statcan.gc.ca/pub/84-215-x/2011001/tbl/t003-eng.pdf (Accessed December 5, 2011).

2. Statistics Canada. Suicides and suicide rate, by sex and by age group, 2008 . Available at: http://www40.statcan.gc.ca/101/cst01/hlth66d-eng.htm (Accessed December 5, 2011).

3. World Health Organization. Suicide Prevention. Available at: http://www.who.int/mental_health/prevention/suicide/suicideprevent/en/ index.html (Accessed December 5, 2011).

4. Insel B, Gould M. Impact of modeling on adolescent suicidal behavior. Psychiatr Clin North Am 2008;31(2):293-316.

5. Värnik A, Kõlves K, Allik J, Arensman E, Aromaa E, van Audenhove C, et al. Gender issues in suicide rates, trends and methods among youths aged 15-24 in 15 European countries. J Affect Disord 2009;113(3):216-26.

6. Bursztein C, Apter A. Adolescent suicide. Curr Opin Psychiatry 2009;22(1):1-6.

7. Beautrais AL. Gender issues in youth suicidal behaviour. Emerg Med 2002;14(1):35-42.

8. Mohler B, Earls F. Trends in adolescent suicide: Misclassification bias? Am I Public Health 2001;91(1):150-53.

9. Parais J, Kreiger N, Tomlinson G, Adlaf E. The validity of the certification of manner of death by Ontario Coroners. Ann Epidemiol 2006;16(11):805-11.

10. Grøholt B, Ekeberg O. Suicide in young people under 15 years: Problems of classification. Nord J Psychiatry 2003;57(6):411-17.

11. Crepeau-Hobson F. The psychological autopsy and determination of child suicides: A survey of medical examiners. Arch Suicide Res 2010;14(1):24-34.

12. Government of Ontario. Coroners Act, R.S.O. 1990, Chapter C. 37. Available at: http://www.e-laws.gov.on.ca/html/statutes/english/elaws_statutes_90c37_e.htm (Accessed December 5, 2011)

13. Landis JR, Koch GG. The measurement of observer agreement for categorical data. Biometrics 1977;33(1):159-74.

14. Paediatric Death Review Committee. Report of the Paediatric Death Review Committee: Annual Report 2009. Toronto, ON: Office of the Chief Coroner, Province of Ontario, 2009.

15. Mishara BL. Conceptions of death and suicide in children aged 6 to 12 and their implications for suicide prevention. Suicide Life Threat Behav 1999;29(2):105-18.

16. Iron K, Zagorski B, Sykora K, Manuel D. Living and dying in Ontario: An opportunity for improved health information. ICES Investigative Report. Toronto, ON: Institute for Clinical Evaluative Sciences, 2008.
17. Wilkins R. PCCF + Version 5E User's Guide (Geocodes/PCCF): Automated Geographic Coding based on the Statistics Canada Postal Code Conversion Files. Ottawa, ON: Statistics Canada, 2009.

18. Statistics Canada. Geographic Units: Dissemination Area (DA). Available at: http://geodepot.statcan.ca/2006/Reference/COGG/LongDescription_e.jsp?GE O_LEVEL=35\&REFCODE=10\&TYPE=L (Accessed June 20, 2011).

19. Wyatt J, Squires T, Collis S, Broadley R. Road traffic suicides. J Forensic Leg Med 2009;16(4):212-14.

20. Conolly J, Cullen A, McTigue O. Single road traffic deaths-accident or suicide? Crisis 1995;16(2):85-89.

21. Murray D, de Leo D. Suicidal behavior by motor vehicle collision. Traffic Inj Prev 2007;8(3):244-47.

22. Schenker N, Gentleman JF. On judging the significance of differences by examining the overlap between confidence intervals. Am Stat 2001;55(3):18286

23. Rockett I, Hobbs G, De Leo D, Stack S, Frost J, Ducatman A, et al. Suicide and unintentional poisoning mortality trends in the United States, 1987-2006: Two unrelated phenomena? BMC Public Health 2010;10:705.

24. Steinberg L. Adolescents' risky driving in context. J Adolesc Health 2011;49(6):557-58.

25. Stanistreet D, Gabbay M, Jeffrey V, Taylor S. Are deaths due to drug use among young men underestimated in official statistics? Drugs: Education, Prevention and Policy 2004;11(3):229-42.

Received: January 4, 2012

Accepted: March 31, 2012

\section{RÉSUMÉ}

Objectifs : Déterminer si les différences attestées dans les taux de suicide des hommes et des femmes subsistent lorsqu'on les corrige pour d'éventuelles erreurs de classification des décès chez les enfants et les jeunes.

Méthode : Cette étude rétrospective descriptive porte sur 1294 suicides, 961 décès accidentels et 254 décès indéterminés survenus entre le $1^{\text {er }}$ janvier 2000 et le 31 décembre 2007 chez les personnes de 10 à 25 ans en Ontario, au Canada. À l'aide des données des dossiers des coroners, nous avons reclassifié les causes de décès en fonction de deux critères de classification erronée différents. Les taux de suicide actuels et reclassifiés ont été calculés selon le sexe et le groupe d'âge (avec des intervalles de confiance de $95 \%$ ) et selon l'année du décès.

Résultats : Les hommes de 16 à 25 ans représentaient la majorité des suicides (68,9\%). L'asphyxie était la cause de suicide la plus courante chez les deux sexes. Les suicides par balle étaient presque exclusivement le fait des hommes, mais les suicides par intoxication à l'alcool, aux drogues ou aux médicaments étaient sensiblement plus élevés chez les femmes. Avant et après la reclassification des décès par suicide, des différences entre les sexes dans les taux de suicide ont été observées dans le groupe des 16 à 25 ans. Pour chaque année de l'étude, les taux de suicide actuels et reclassifiés étaient plus élevés chez les hommes que chez les femmes.

Conclusions : Les différences observées à l'adolescence dans les taux de suicide des hommes et des femmes ne sont probablement pas dues à des erreurs de classification. D'autres explications proposées des différences entre les sexes dans les taux de suicide des jeunes mériteraient des études plus poussées.

Mots clés : suicide; adolescent; enfant; cause de décès; différences entre les sexes; classification erronée du suicide 